\title{
Standardization of an isolated pig heart preparation with parabiotic circulation: methodological considerations
}

O. Petrucci Júnior, P.P.M. Oliveira, M.R. Carmo, R.W. Vieira and D.M. Braile
Departamento de Cirurgia Cardíaca, Universidade Estadual de Campinas, Campinas, SP, Brasil

\author{
Correspondence \\ O. Petrucci Júnior \\ Departamento de Cirurgia Cardíaca \\ Universidade Estadual de Campinas \\ Rua João Baptista Geraldi, 135 \\ 13085-852 Campinas, SP \\ Brasil \\ Fax: 19-3249-0051 \\ E-mail: petruccijr@uol.com.br
}

Publication supported by FAPESP.

Received August 20, 2002

Accepted January 8, 2003

\begin{abstract}
In the present study we standardized an experimental model of parabiotic circulation of isolated pig heart. The isolated heart was perfused with arterial blood from a second animal as support and submitted to regional ischemia for $30 \mathrm{~min}$, followed by total ischemia for $90 \mathrm{~min}$ and reperfusion for $90 \mathrm{~min}$. Parameters for measurement of ventricular performance using different indices measured directly or indirectly from intraventricular pressure were defined as: maximum peak pressure, final diastolic pressure, pressure developed, first derivative of maximum pressure $\left(\mathrm{dP} / \mathrm{dt}_{\max }\right)$, first derivative of minimum pressure $\left(\mathrm{dP} / \mathrm{dt}_{\min }\right)$, systolic stress of the left ventricle $\left(\sigma_{\mathrm{s}}\right)$, and maximum elastance of the left ventricle. Isolated hearts subjected to regional and global ischemia presented significant worsening of all measured parameters. Less discriminative parameters were $\mathrm{dP} / \mathrm{dt}_{\max }$ and $\mathrm{dP} /$ $\mathrm{dt}_{\min }$. Elastance was the most sensitive parameter during the reperfusion period, demonstrating an early loss of ventricular function during reperfusion. The model proved to be stable and reproducible and permitted the study of several variables in the isolated heart, such as ischemia and reperfusion phenomena, the effects of different drugs, surgical interventions, etc. The model introduces an advantage over the classical models which use crystalloid solutions as perfusate, because parabiotic circulation mimics heart surgery with extracorporeal circulation.
\end{abstract}

\section{Introduction}

Oscar Langendorff was the first to describe a method to investigate mechanical activity in isolated mammalian hearts (1). According to Döring (2), the method proposed by Langendorff at the end of the nineteenth century was widely accepted for the mechanical, coronary and metabolic study of
Key words

- Isolated heart

- Ischemia

- Parabiotic circulation

- Reperfusion

- Model 
applicability (4-7).

Although the Langendorff isolated heart preparation with parabiotic circulation is substantially more complex than the classical preparation with the crystalloid solution, its scientific utility has greatly increased. A 10-year survey of the English scientific literature revealed that few references have been made to the standardization of bloodperfused isolated porcine heart models, the anesthesia of the support animal, maintenance of the model or the perfusion time achieved. Thus, the objective of the present study was to describe the standardization of an isolated porcine heart model with parabiotic circulation.

\section{Material and Methods}

\section{Animal model}

Pigs aged on average 15 weeks were used because of their similarity to humans in terms of anatomy and ischemic response $(8,9)$. Each experiment utilized two animals; the heavier animal weighing approximately 40 $\mathrm{kg}$ was the support animal and the lighter animal weighing approximately $20 \mathrm{~kg}$ supplied the isolated heart.

Support animal. Preanesthetic medication applied intramuscularly consisted of 1 $\mathrm{mg}$ atropine and $25 \mathrm{mg} / \mathrm{kg}$ ketamine. An intravenous injection containing $12.5 \mu \mathrm{g} / \mathrm{kg}$ fentanyl, $15 \mathrm{mg} / \mathrm{kg}$ pentobarbital and $8 \mathrm{mg}$ pancuronium bromide was then performed. A $12.5-\mathrm{mg} / \mathrm{kg}$ dose of ketamine was applied hourly and a 1-mg dose of pancuronium bromide whenever needed (10). An orotracheal tube was inserted and the animal was placed on volume mechanical ventilation.

Animal donor. The preanesthetic medication applied intramuscularly contained 1 $\mathrm{mg}$ atropine and $25 \mathrm{mg} / \mathrm{kg}$ ketamine. A dose of $20 \mathrm{mg} / \mathrm{kg}$ pentobarbital was administered after establishing a venous access. An orotracheal tube was inserted and the animal was placed on pressurized mechanical ventilation.

\section{Surgical technique}

Support animal. Bilateral cervicotomy was performed to cannulate the left internal jugular vein (venous access), the left carotid (to monitor mean arterial pressure), the right internal jugular (perfusion system venous return), and the right carotid (perfusion system arterial blood). Heparin (500 IU/kg) was injected into the left internal jugular.

Animal donor. Median sternotomy. A dose of $500 \mathrm{IU} / \mathrm{kg}$ heparin was injected into the right atrium. The inferior and superior venae cavae were occluded and the heart was rapidly excised. The largest possible portion of the right atrium was removed, with preservation of the right coronary artery. The mitral valve was destroyed by sectioning the chordae tendineae and flaps and the mitral ring were closed with 2.0 polyester purse string sutures. A needle thermometer was inserted into the interventricular septum and a previously prepared latex balloon was inserted into the left ventricular cavity, which was then fixed to a plastic support and tied to the mitral ring. During this procedure, the apex of the left ventricle was perforated to permit drainage of blood from the Thebesian system of the left ventricle. A cannula was inserted into the ascending aorta and tied with a 3.0 polyester polyfilament to allow coronary perfusion via the aorta. The anterior interventricular coronary artery was dissected to permit placement of the minivascular clip at the appropriate time. A cannula was connected to the aorta with a previously prepared perfusion system and infusion of the aorta was started.

Perfusion system. The system was planned so that it would permit continuous retrograde perfusion of the isolated heart at a constant pressure, independent of the support animal's arterial pressure (Figure 1).

\section{Experimental methodology}

Perfusion of the isolated heart coronaries 
was initiated and the myocardial septum temperature was expected to reach $36^{\circ} \mathrm{C}$. In case of ventricular fibrillation, 5 -joule shocks were applied to reestablish orderly electrical activity of the isolated heart. The model was stabilized for $20 \mathrm{~min}$ while the intraventricular pressure was measured. This was followed by the induction of myocardial regional ischemia, which was standardized by dissecting the anterior interventricular branch before the first diagonal branch and occluding it for $30 \mathrm{~min}$.

After $30 \mathrm{~min}$ of regional ischemia, the microvascular clip was withdrawn, the heart was subjected to global ischemia for $90 \mathrm{~min}$ and reperfusion was initiated. The heart was defibrillated when the septal temperature reached $36^{\circ} \mathrm{C}$ and the pressure measured every $30 \mathrm{~min}$ for a period of $90 \mathrm{~min}$.

Atrial pacemakers with a frequency of $160 \mathrm{bpm}$ were used to stimulate all the isolated hearts. At the end of this procedure, the support animal was sacrificed. The isolated heart as well as the right ventricular wall, the atria and blood vessels were dissected according to the technique of Brooks et al. (11), and the left ventricle was weighed on an analytical scale to obtain its wet weight.

\section{Method for the measurement of intraventricular pressure}

The balloon introduced through the mitral ring after the destruction of the valve had a plastic support $1.5 \mathrm{~cm}$ in diameter. This plastic support permitted two catheters having an internal diameter of $2 \mathrm{~mm}$ to communicate with the balloon in such a way that during infusion of volume the pressure developed by the balloon in the left ventricle was also measured. The balloon was specifically designed to hold a volume of $60 \mathrm{ml}$ without an increase in its internal pressure.

After stabilizing the isolated heart for 20 $\mathrm{min}, 5 \mathrm{ml}$ saline was injected into the balloon at 1-min intervals to stabilize the intraventricular pressure. The largest possible vol- ume of the balloon that maintained the diastolic pressure at $0 \mathrm{mmHg}$ was determined. This volume was denoted $\mathrm{V}_{0}$ and was then increased $2 \mathrm{ml}$ at a time until the pressure developed by the left ventricle reached its maximum value. This volume was denoted $\mathrm{V}_{\max }$. This method, described by Strömer et al. (12), utilized the $V_{\max }$ to normalize the ventricular volume used for plotting and comparing data.

Two functional points of the volume pressure curve, 50 and $100 \%$ of $V_{\max }$, were used to compare the results.

In addition, the following intraventricular pressure data were obtained: maximum peak pressure, final diastolic pressure, pressure developed, first derivative of maximum pressure $\left(\mathrm{dP} / \mathrm{dt}_{\max }\right)$, first derivative of minimum pressure $\left(\mathrm{dP} / \mathrm{dt}_{\text {min }}\right)$, systolic stress of the left ventricle $\left(\sigma_{\mathrm{s}}\right)$, and maximum elastance of the left ventricle $\left(\mathrm{E}_{\max }\right)$.

Systolic stress of the left ventricle was

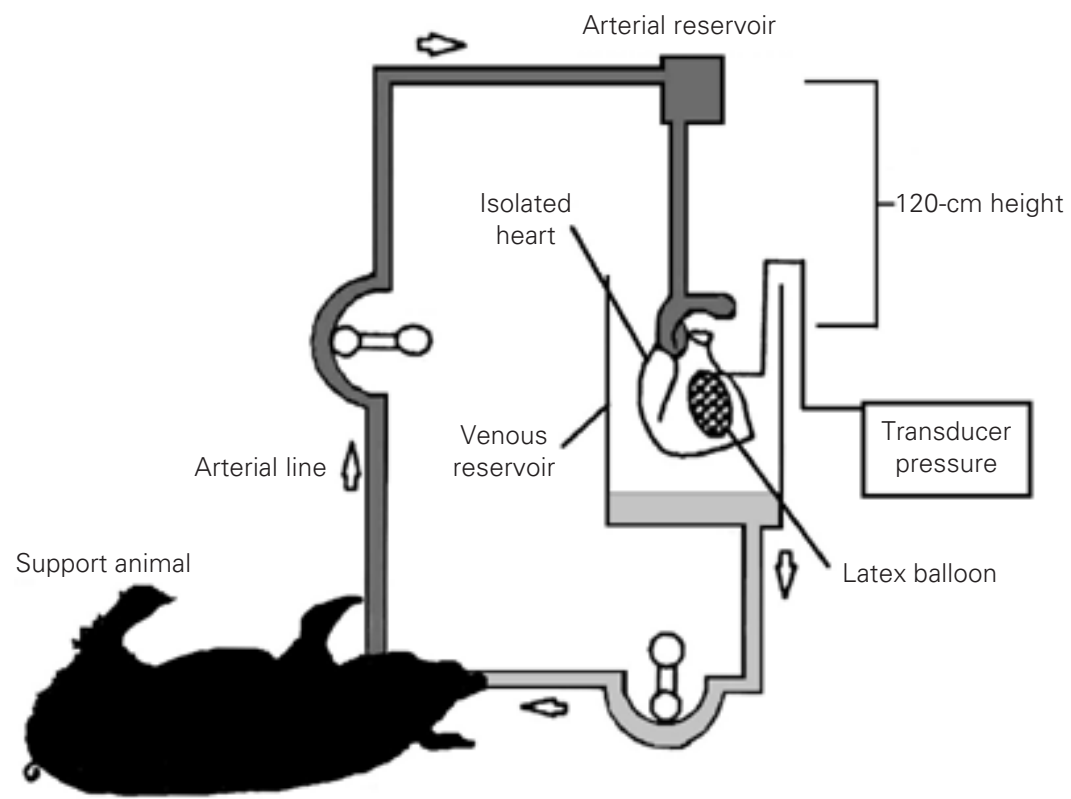

Figure 1. Diagram of the perfusion system in the isolated heart. Dark gray color is used to represent arterial blood. The arterial pump sends the blood to the conventional cardiotomy reservoir, which is located $120 \mathrm{~cm}$ above the isolated heart. The venous reservoir has a heat exchanger that warms the effluent blood from the isolated heart and returns it to the support animal through another pump that is represented in light gray. The intraventricular balloon is connected to a monitor to measure intraventricular pressure. 
obtained using the measurements of ventricular pressure, balloon volume, and weight of left ventricle (11).

The radius of the left ventricle, $R_{1}$, was calculated using the formula: $R_{1}{ }^{1 / 3}=V_{b} / 4 /$ $3 \pi$, where $V_{b}=$ volume of the intraventricular balloon assuming that the shape of the left ventricle is spherical.

The volume of the left ventricle is the total volume of the balloon plus the volume of the left ventricle wall. The formula for determining the volume of the left ventricle is: volume of the left ventricle wall = weight of left ventricle/1.05, where 1.05 is the specific density of the myocardium. Volume of the ventricle $\left(V_{L}\right)=4 / 3 \pi\left(R_{1}+h\right)^{3}$ and $h=$ $\left(V_{b} / 4 / 3 \pi\right)^{1 / 3}-R_{1}$, where $h$ is the thickness of the left ventricle wall.

Systolic stress was calculated according to the Laplace Law as described by Mirsky (13): $\sigma_{s}=P_{s}\left[\left(R_{1}^{2} / h\right) /\left(2 R_{1}+h\right)\right]$, where $P_{s}$ is the maximum systolic pressure, $R_{1}$ is the radius of the left ventricle with a determined volume in the balloon, and $\mathrm{h}$ is the thickness of the left ventricle wall.

$\mathrm{E}_{\max }$ was calculated by linear regression of the maximum systolic curves obtained for intraventricular volume as described by Suga (14).

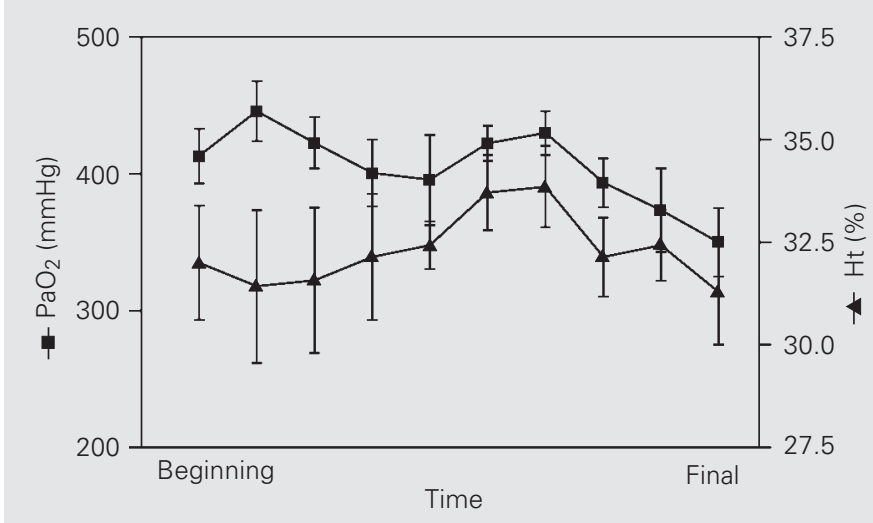

Figure 2. Perfusion parameters of the isolated heart. Hematocrit was constant without transfusions. The mean hematocrit ( $\mathrm{Ht}$, triangles) value of perfused blood was $31.30 \pm 3.40 \%(95 \% \mathrm{Cl}, 28.14$ to $34.43 \%)$. No significant differences were observed for any of the intervals studied. The oxygen supply to the isolated heart remained constant $\left(\mathrm{PaO}_{2}\right.$, squares), never reaching values of less than $300 \mathrm{mmHg}$. Data are reported as means \pm 2 SEM.

\section{Statistical analysis}

Data are reported as means $\pm 2 \mathrm{SEM}$. The Student $t$-test was used to compare data obtained before and after global ischemia in the samples studied. Analysis of variance (ANOVA) was used to assess variations in the gasometric parameters and the Dunnett test to identify the differences between groups.

ANOVA was also used to evaluate elastance and compliance and the Dunnett test to identify the differences between groups.

The statistical package Graph Pad Prism 3.0 version for Windows (Graph Pad Software, San Diego, CA, USA, www.graphpad.com) was used for all statistical calculations, with the level of significance set at $\mathrm{P}<0.05$.

\section{Results}

\section{Perfusion parameters}

The initial hematocrit of perfused blood was $32.00 \pm 3.70 \%$ (95\% CI, 28.58 to $35.42 \%$ ), with variations during the experiment as demonstrated in Figure 2. The mean hematocrit value of perfused blood was 31.30 $\pm 3.40 \%$ ( $95 \%$ CI, 28.14 to $34.43 \%$ ). No significant differences were observed for any of the intervals studied. The oxygen supply to the isolated heart remained constant, never reaching values of less than $300 \mathrm{mmHg}$ (Figure 2).

\section{Isolated heart after regional and global ischemia}

Reperfusion of the hearts was performed after $30 \mathrm{~min}$ of regional ischemia and $90 \mathrm{~min}$ of global ischemia, and intraventricular pressure and its derivatives were observed every $30 \mathrm{~min}$.

Figure 3 illustrates the values obtained with $90 \mathrm{~min}$ of reperfusion for systolic and 
diastolic pressure in comparison with values obtained during the control period. Diastolic pressure did not differ significantly from control at the 30- and 60-min reperfusion periods, but at the 90-min period a significant difference was observed compared to control.

Table 1, which shows $100 \% \mathrm{~V}_{\max }$ values, demonstrated that systolic pressure was a differentiating factor that indicated deterioration for all the periods studied that was significantly different from the control group.

The pressure developed during all periods showed a significant reduction compared to control (Figure 4).

There was a significant reduction in $\mathrm{dP} /$ $\mathrm{dt}_{\max }$ compared to control for all periods studied and a significant reduction in $\mathrm{dP} /$ $\mathrm{dt}_{\text {min }}$ compared to control for only two periods of study (Figure 5).

There was a significant reduction in systolic stress $\left(\sigma_{\mathrm{s}}\right)$ compared to control for all periods studied (Figure 6). The elastance values decreased significantly in comparison with the control at 30, 60 and 90 min of reperfusion (Figure 7).

\section{Discussion}

\section{Support animal}

A smaller animal donor was a better option because a large heart was not needed to obtain the parameters required for this study and the costs of the experiment were reduced.

The mean time required for the removal of the heart and for initiating perfusion of the isolated heart was $815.7 \pm 109 \mathrm{~s}$, similar to literature data regarding similar experiments conducted on cats and rats (15-17).

The mean weight of the donor animals was $22.00 \mathrm{~kg}$, which was an adequate size for manipulating the heart, especially when the maximum volume of the latex balloon installed within the left ventricle was standardized. Therefore, the utilization of smaller animals does not seem to be a limiting factor. The use of smaller hearts in the preparation of the "working heart" type may be more

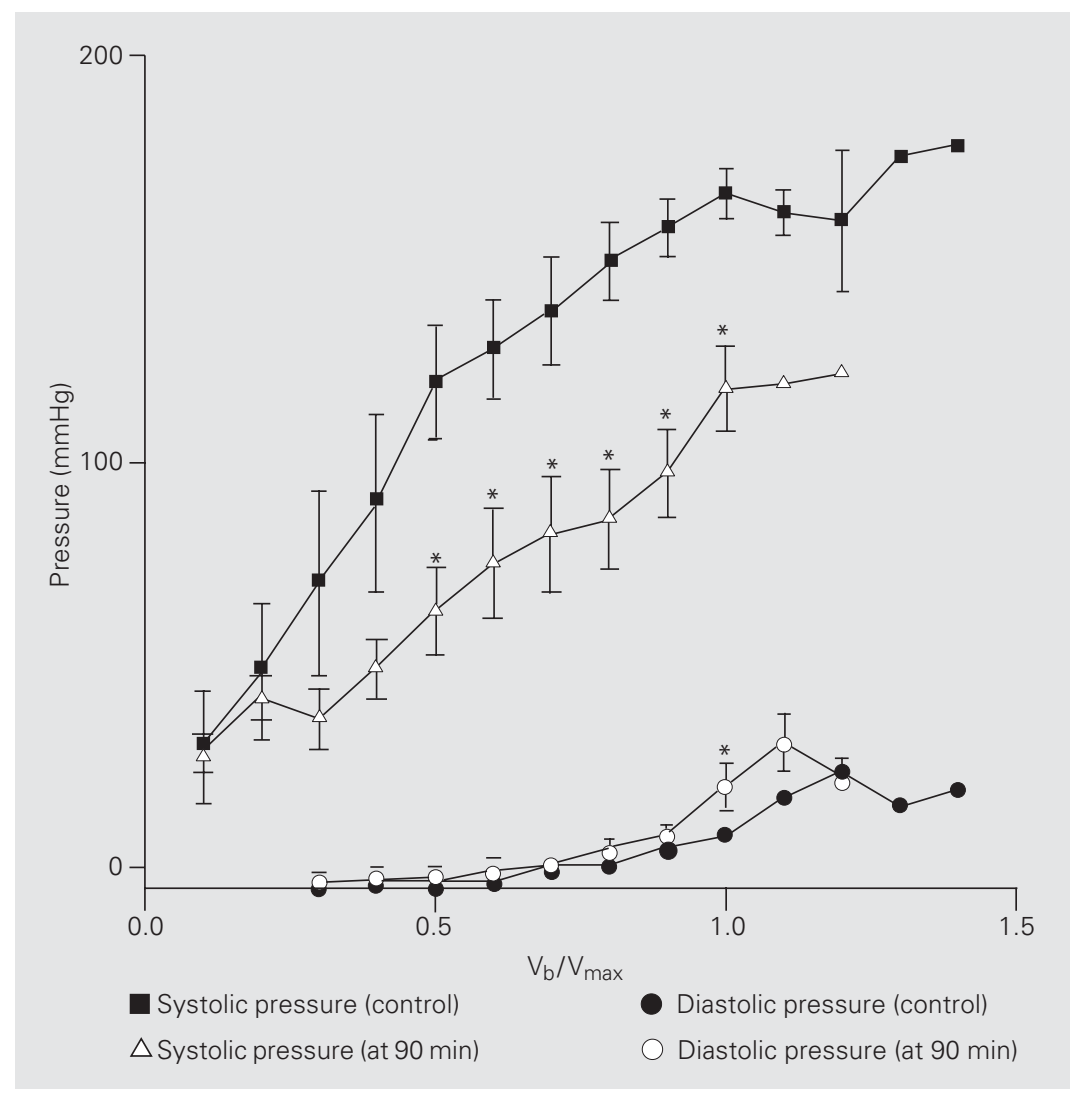

Figure 3. Systolic and diastolic pressure during the control period and after 90-min reperfusion. Data are reported as means \pm 2 SEM. ${ }^{*} \mathrm{P}<0.05$ compared to respective control (Student $t$-test).

\begin{tabular}{|c|c|c|c|c|}
\hline \multirow[t]{2}{*}{ Parameters } & \multirow{2}{*}{$\begin{array}{l}\text { Control } \\
(\mathrm{N}=7)\end{array}$} & \multicolumn{3}{|c|}{ Reperfusion } \\
\hline & & $30 \min (N=7)$ & $60 \min (N=7)$ & $90 \min (N=6)$ \\
\hline$P_{s}$ & $163.30 \pm 6.21$ & $131.70 \pm 4.60^{*}$ & $131.70 \pm 8.24^{*}$ & $100.70 \pm 9.62 *$ \\
\hline$P_{d}$ & $7.43 \pm 1.56$ & $11.14 \pm 4.73$ & $14.00 \pm 5.95$ & $19.50 \pm 4.73^{*}$ \\
\hline$P_{\text {dev. }}$ & $156.30 \pm 5.71$ & $121.90 \pm 8.79^{*}$ & $116.60 \pm 0.85^{*}$ & $100.00 \pm 9.67^{*}$ \\
\hline $\mathrm{dP} / \mathrm{dt}_{\max }$ & $1418.00 \pm 71.15$ & $1188.00 \pm 93.70^{*}$ & $1159.00 \pm 93.30^{*}$ & $1027.00 \pm 31.40^{*}$ \\
\hline $\mathrm{dP} / \mathrm{d} t_{\min }$ & $-889.00 \pm 73.45$ & $-858.10 \pm 86.21$ & $-768.90 \pm 63.04$ & $-710.80 \pm 60.79$ \\
\hline$\sigma_{\mathrm{s}}$ & $161.60 \pm 4.45$ & $102.70 \pm 14.02^{*}$ & $110.70 \pm 6.90^{*}$ & $101.00 \pm 0.18^{*}$ \\
\hline
\end{tabular}

Observe that with 30,60 and 90 min reperfusion, all parameters, except $\mathrm{dP} / \mathrm{dt}$ min, were significantly different compared to $100 \% V_{\text {max }}$. $V_{\text {max }}$ : maximum value; $P_{s}$ : maximum peak pressure; $P_{d}$ : final diastolic pressure; $P_{\text {dev. }}$ : pressure developed; $d P / d t_{\max }$ and $d P / d t_{\min }$ : first derivative of maximum and minimum pressures, respectively; $\sigma_{s}$ : systolic stress of the left ventricle.

${ }^{*} \mathrm{P}<0.05$ compared to control values (Student $t$-test) 
Figure 4. Pressure developed during the control period and after 90 -min reperfusion. Data are reported as means \pm 2 SEM. ${ }^{*} \mathrm{P}<0.05$ compared to control (Student $t$-test).
Figure 5. First derivative of maximum $\left(d P / d t_{\text {max }}, A\right)$ and minimum $\left(\mathrm{dP} / \mathrm{dt}_{\min }, \mathrm{B}\right)$ pressures during the control period and after 90min reperfusion. Data are reported as means \pm 2 SEM. ${ }^{*} P<0.05$ compared to control (Student $t$-test). interesting because the cardiac output developed will be proportional. This means less blood circulating in the system and less damage to blood components.

Porcine models were chosen because the coronary anatomy and circulatory system of these animals are similar to those of man $(8,9)$. The collateral coronary system is also similar because both species have few preexisting collateral coronary arteries, although they have the capacity to develop a collateral circulatory system after myocardial infarction (18). Although the myocardial collateral circulation in humans is heterogeneous, the porcine heart can be used as a highly sensitive model for the study of therapeutic interventions (19). A big difference in the porcine and human vascular anatomy is the hemiazygous vein that drains directly into the coronary sinus, but this did not interfere
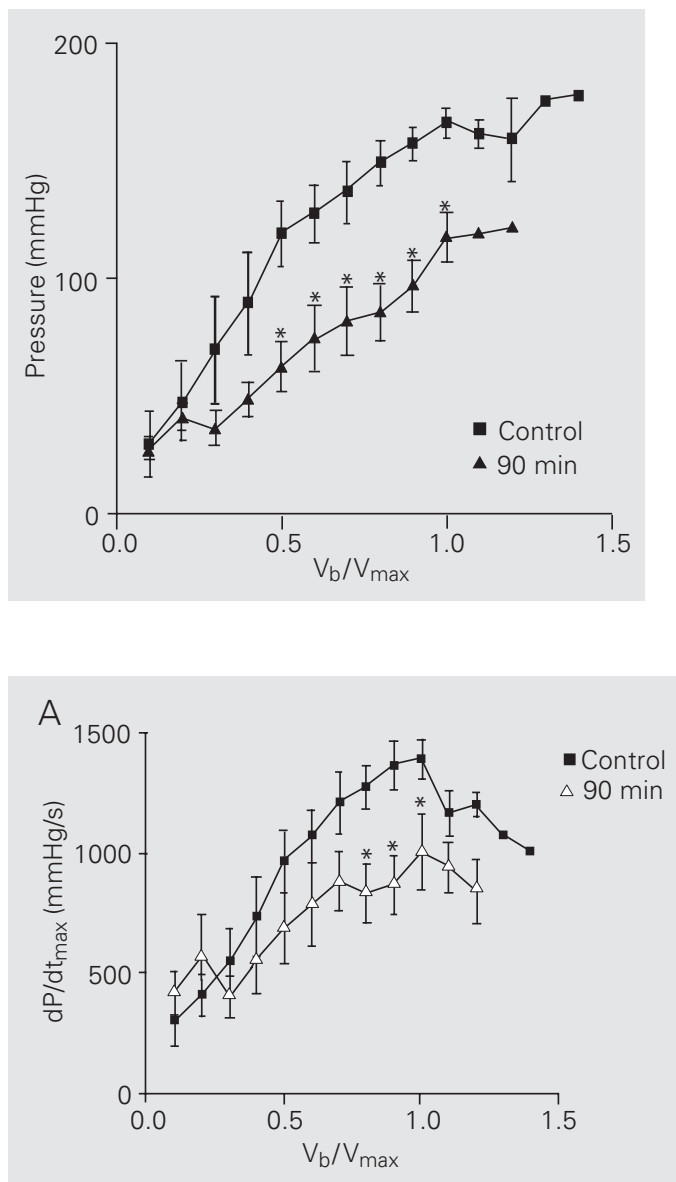

with any phase of the experiment. Since none of the cases required therapeutic transfusion, there was no need for blood typing. The use of a large support animal and a small volume of crystalloid solution were initially effective in maintaining almost normal hematocrit levels. Vasoactive drugs were not needed to maintain the support animal, which was an important factor since these drugs could cause secondary problems in the isolated heart, involving the inclusion of another variable in the protocol or the use of another vasoactive group of drugs.

\section{Perfusion circuit}

The perfusion circuit of the isolated heart with a conventional cardiotomy reservoir placed at a height of $120 \mathrm{~cm}$ was very practical. The perfused heart model at constant pressure excluded the variations in the performance of an isolated heart dependent on the perfusion pressure.

Perfusion of the heart with different pressures produces a varied performance of ventricular function. Hence, when the perfusion pressure is approximately $50 \mathrm{mmHg}$, the performance is inferior to that at $90-\mathrm{mmHg}$ pressure (20). Another reason for using constant pressure was to avoid conflicting results when using a constant perfusion flow model. The models that use a constant flow in coronary perfusion present perfusion pressure variations due to their high or low resis-

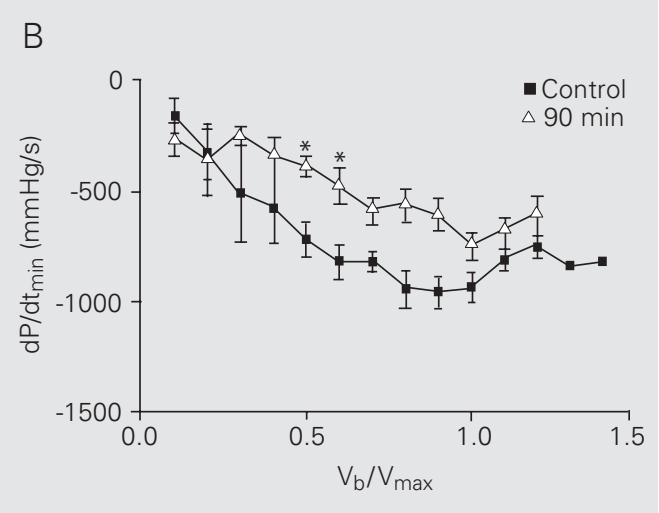


tance. This could result in a better or poorer ventricular performance and also in changes in myocardial oxygen consumption secondary to the Gregg phenomenon (21). This phenomenon has been discussed in the literature and some points are cited below:

1) Hypoperfusion: the best performance is secondary to an increase in coronary perfusion pressure resulting from an initial hypoperfusion of the myocardium. This is a pathological explanation of the Gregg phenomenon as a nonphysiological fact (22).

2) It has been suggested in the literature that the Gregg phenomenon only occurs in a "nonworking heart" (23). However, this suggestion is not often supported in the literature. Other investigators have observed this phenomenon in the "working heart" (24), which contradicts the findings by Ross Jr. et al. (23).

3) Distention of the coronary arteries as proposed by Lochner et al. (25): an increase in coronary perfusion pressure produces distension, which causes distention of the surrounding myocardial fibers resulting in improved cardiac performance secondary to the Frank-Starling mechanism.

4) Oxygen flow and supply: according to Abel and Reis (26), in the absence of previous ischemia, an increased cardiac performance in the Gregg phenomenon is secondary to an increase in the flow and supply of oxygen. In this case, the Gregg phenomenon would only be a physiological response.

Hence, it seems reasonable to conclude that the Gregg phenomenon occurs and can be observed in working and nonworking heart preparations as long as they are not grossly hypoperfused and the coronary circulation remains intact. Another finding related to the Gregg phenomenon is the Anrep effect.

Knowlton and Starling (27), in 1912, observed that a rapid increase in aortic pressure increased resistance to the flow in isolated heart-lung preparations, causing a positive inotropic effect on the isolated heart, which results in a gradual reduction of the diastolic volume of the left ventricle after a transitory dilation. In 1912, Anrep (28) also described this phenomenon. This slow improvement in cardiac function, a few seconds after an increase in aortic pressure, was called the Anrep phenomenon (29).

According to Monroe et al. (30), this is due to momentary subendocardiac ischemia and redistribution of the secondary flow. Although the Anrep effect on working or nonworking hearts with constant flow or constant pressure as proposed by Monroe et al. (30) is debatable, no study has been conducted to test this hypothesis (29). Based on the data cited above, we opted for a model with constant pressure in order to avoid variable performance related to the Gregg phenomenon and the Anrep effect and not to interventions in the isolated heart.

The chamber prepared to receive the effluent blood proved to be adequate as it accommodated the isolated heart well and
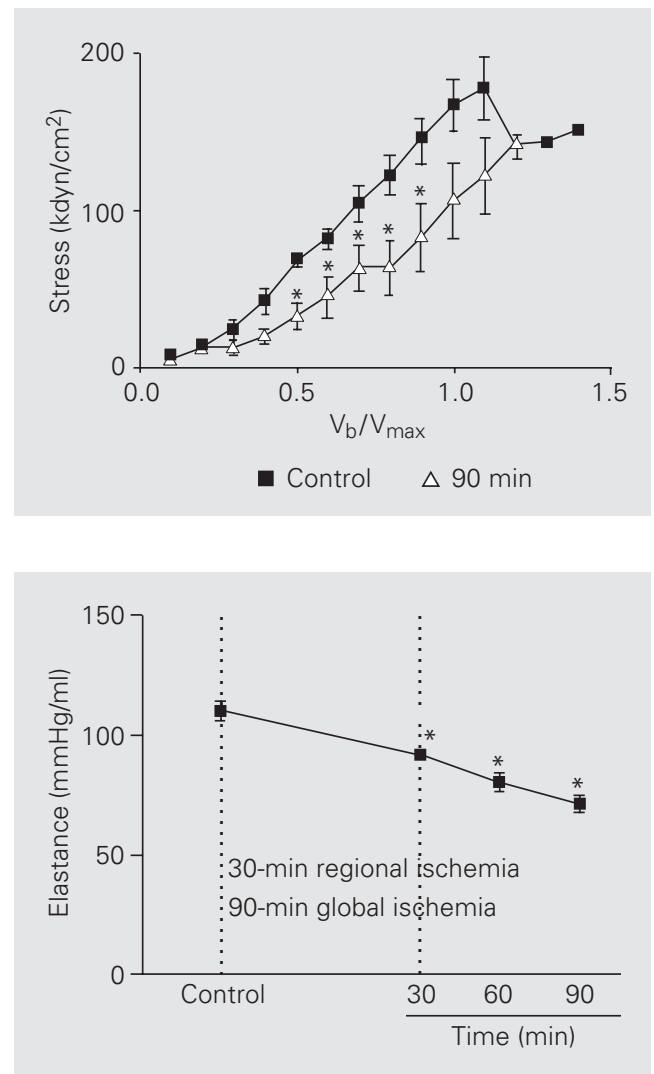

Figure 6. Systolic stress of the left ventricle. Data are reported as means \pm 2 SEM. ${ }^{*} \mathrm{P}<0.05$ compared to control (Student $t$ test).

Figure 7. Values of elastance of the left ventricle for the different periods of reperfusion and control. Data are reported as means \pm 2 SEM. ${ }^{*} P<0.05$ compared to control (ANOVA). 
had an efficient heat exchanger that warmed the blood returning to the support animal.

Polyvinyl tubes measuring $1 / 4$ inch in internal diameter were used so that the initial filling volume was small, as shown by the minimum hematocrit variation of the support animal.

The same system but with smaller reservoirs and tubes with small internal diameters may be used for smaller animals.

\section{Perfusion parameters to the isolated heart}

Characterization of the perfusion of the isolated heart is important as it guarantees the control of variables such $\mathrm{pH}$, electrolytes and hematocrit.

Although Heymans and Kochmann (3) described parabiotic circulation in 1904, it was only recently that the procedure started to be used more frequently. Pasini et al. (5) recently described the characterization of this model with regard to the response of the support animal to anesthesia, heparinization and parabiotic circulation. Anesthetic induction and maintenance did not interfere with the arterial pressure of the support animal. Hemodynamic stability was good and in accordance with the findings of Pasini et al. (5).

There was no need for transfusion since the hematocrit level of the support animal remained stable, also in agreement with Pasini et al. (5) and Budrikis et al. (31). This is mainly because only a small volume was needed to fill the perfusion system and to return all the blood to the support animal. Saline $(0.9 \%)$ was chosen to fill the system because it was easily available and did not contain potassium, with consequent reduced costs.

The partial pressure of oxygen supplied to the isolated heart was always above 300 $\mathrm{mmHg}$, without a statistically significant variation. These data agree with those obtained by Budrikis et al. (31) who used parabiotic circulation in pigs with the $\mathrm{PaO}_{2}$ always above $300 \mathrm{mmHg}$. Li et al. (20) utilized parabiotic circulation during $6 \mathrm{~h}$ of perfusion with the $\mathrm{PaO}_{2}$ always higher than 200 $\mathrm{mmHg}$ and obtained results very similar to those obtained in the present study.

In our study, we did not measure the circulating catecholamines but Pasini et al. (5) showed that they increased after anesthesia and surgical manipulation, an event closely similar to the situation to which a patient is submitted during extracorporeal circulation.

Monroe et al. (15) demonstrated the role of the support animal in relation to the supply of catecholamines and its possible action in clearance produced by the isolated heart in dogs with parabiotic circulation. In their experiment, they excluded the support animal after stabilization and perfused the isolated heart with an isolated lung. There was a reduction in the effluent catecholamines in parallel to a fall in cardiac performance. On returning perfusion to the support animal, the catecholamines again increased and the performance also improved, regaining original values.

After the introduction of heparin and perfusion of the isolated heart, another similarity observed between this parabiotic circulatory model and the clinical situation was the increase in the level of fatty acids circulating as a result of the action of heparin on the endothelial lipase and the liberation of catecholamines (5). Without any doubt, this increase in fatty acids influences the cardiac metabolism, which makes this model especially interesting because the metabolic changes and the myocardial perfusion conditions are similar to those that occur in human hearts submitted to extracorporeal circulatory surgery. The isolated heart predominantly uses fatty acids in its metabolism and this is very close to clinical reality (32).

Masuda et al. (4) demonstrated that the performance of crystalloid-perfused hearts depended on the perfusion pressure. Blood perfused hearts presented fewer variations in performance when there were great varia- 
tions in perfusion pressure. This indicated that preparations using blood had greater applicability in therapeutic interventions.

Isolated hearts respond differently to therapeutic intervention depending on whether the perfusion is done with blood or crystalloid solutions. When blood preparations are utilized, the responses of the heart are more similar to those observed in clinical practice than in the case of crystalloid-perfused hearts (6).

This demonstrates the utility of the model used in this study, which is ideal for the study of cardiac performance under different perfusion conditions using different substrates, drugs and surgical interventions, etc.

\section{Methodology for the measurement of ventricular parameters}

Langendorff type preparations have often been used to measure contractile function (12). Nevertheless, a common problem is comparing different hearts in different situations. The hearts may vary in size, degree of hypertrophy or dilation.

Heart rate, temperature and perfusion parameters can be normalized but the intraventricular volume cannot be fixed.

Various strategies have been described. Brooks et al. (11) studied hypertrophied hearts and set a reference volume of $0.025 \mathrm{ml} / \mathrm{kg}$ for the donor animal, which is used for comparing different hearts. Eberli et al. (33), Feldman et al. (34), and Lorell et al. (35) studied hearts with concentric ventricular hypertrophy and fixed the ventricular volume for a diastolic pressure of $10 \mathrm{mmHg}$. Glass et al. (36) used the necessary intraventricular volume $\left(\mathrm{V}_{\max }\right)$ to compare maximum peak pressure developed. This strategy is very similar to the methods used to study papillary muscles, whereby the investigator measures the length of the longest papillary muscle $\left(\mathrm{L}_{\max }\right)$ to determine the highest developed tension. As $\mathrm{L}_{\max }$ standardizes the other values, it is possible to compare vary- ing lengths of papillary muscles (12).

In the present study, the ventricular volume was incremented and standardized by $\mathrm{V}_{\max }$ and the curves obtained for each reading were compared with 50 and $100 \% \mathrm{~V}_{\max }$ situations.

According to Strömer et al. (12), 50\% $\mathrm{V}_{\max }$ was sufficient to determine the differences when conducting any kind of study on hearts. The authors emphasized the standardization of intraventricular volume followed by a comparison of the hearts in terms of the same physiological factor.

In the present study, the physiological factors were assessed with 50 and $100 \%$ $\mathrm{V}_{\text {max }}$, and it was observed that $100 \% \mathrm{~V}_{\text {max }}$ had a greater capacity to demonstrate differences and therefore was the most discerning factor.

The hemodynamic parameters studied were parameters commonly used (2). The physiological aspect at $100 \% \mathrm{~V}_{\max }$ demonstrated significant differences throughout the reperfusion periods in terms of systolic pressure, developed pressure and $\mathrm{dP} / \mathrm{dt}_{\max }$.

Diastolic pressure presented a gradual increase during the reperfusion process with a significant difference only at $90 \mathrm{~min}$ of reperfusion. This occurrence may have been due to very similar values or a greater difficulty in demonstrating alterations in the diastolic function of damaged hearts. As the $\mathrm{dP} /$ $\mathrm{dt}_{\text {min }}$ did not demonstrate statistically significant alterations, it was not a sensitive parameter for diastolic function in this study.

Systolic stress was the only variable that showed statistically significant differences in all the reperfusion periods at 50 and $100 \%$ $\mathrm{V}_{\max }$. According to Brooks et al. (11), it is a highly sensitive measure of the cardiac contractile condition.

Elastance demonstrates its capacity to create pressure when the intraventricular volume increases. Ventricles that function well produce an increase in pressure when they undergo distention in comparison with poorly functioning ventricles. Maximum 
elastance is a highly sensitive indicator for demonstrating deterioration of the myocardial contractile condition. There was a reduction in $\mathrm{E}_{\max } 30$ min after the beginning of perfusion, which deteriorated during its course and reached its maximum fall at 90 min of perfusion. During the reperfusion of the hearts, it was observed that maximum elastance permitted early detection of the ventricular function alterations that occurred during reperfusion of the hearts. This index, which is independent of the preload and afterload, has proved to be highly sensitive to changes in the contractile condition and is in accordance with the findings of Suga (14), Sagawa et al. (37), Burkhoff and Sagawa (38) and Ko et al. (39).

Blood-perfused hearts present smaller variations in coronary blood flow because of viscosity and oncotic properties (12). Although blood flow was not measured in this experiment, we believe that it was very close to clinical reality.

In summary, the model presented is easily executable, provides a heart with controllable variables that help develop different methods of study, but the team involved in the study should undergo a period of training. Further studies using this preparation will achieve greater proximity to clinical reality because of the above cited peculiarities and will provide a powerful tool for the clinical investigation of new drugs and surgical interventions, as well as for studies on ischemia and myocardial reperfusion.

\section{References}

1. Döring HJ \& Dehnert HD (1987). The isolated perfused warmblooded heart according to Langendorff. In: Köberlein K (Editor), Methods in Experimental Physiology and Pharmacology. English edn. Biomesstechnik-Verlag March GmbH, Freiburg, Germany.

2. Döring HJ (1990). The isolated perfused heart according to Langendorff technique - Function - Application. Physiologia Bohemoslovaca, 39: 481-504.

3. Heymans JF \& Kochmann M (1904). Une nouvelle méthode de circulation artificielle à travers le coeur isolé de mammifère. Archives Internationales de Pharmacodynamie et de Thérapie, 13: 531-538.

4. Masuda M, Chang-Chun C, Cho BC \& Flameng W (1994). Coronary reserve and contractile reserve in crystalloid and blood perfused rabbit hearts. Heart and Vessels, 9: 175-182.

5. Pasini E, Solfrini R, Bachetti $T$, Marino M, Bernocchi P, Visioli F \& Ferrari R (1999). The blood perfused isolated heart: characterization of the model. Basic Research in Cardiology, 94: 215-222.

6. Qui Y \& Hearse DJ (1992). Comparison of ischemic vulnerability and responsiveness to cardioplegic protection in crystalloid-perfused versus blood-perfused hearts. Journal of Thoracic and Cardiovascular Surgery, 103: 960-968.

7. Walters III HL, Digerness SB, Naftel DCl, Waggoner III JR, Blackstone EH \& Kirklin JW (1992). The response to ischemia in blood-perfused vs crystalloid-perfused isolated rat heart preparations. Journal of Molecular and Cellular Cardiology, 24: 1063-1077.

8. Sack WO (1982). Essentials of pig anatomy. In: Maughan L (Editor), Veterinary Textbooks. Ithaca, New York, NY, USA.

9. Peng CF, Kane JJ \& Jones EM (1983). The adverse effect of systemic hypertension following myocardial reperfusion. Journal of Surgical Research, 34: 59-67.

10. Flecknell PA (Editor) (1996). Anaesthetic management. In: Laboratory Animal Anaesthesia. A Practical Introduction for Research Workers and Technicians. Academic Press, San Diego, CA, USA.
11. Brooks WW, Healey NA, Sem S, Conrad CH \& Bing OHL (1993). Oxygen costs of stress development in hypertrophied and failing hearts from the spontaneously hypertensive rat. Hypertension, 21: 56-64.

12. Strömer H, Cittadini A, Szymanska G, Apstein CS \& Morgan JP (1997). Validation of different methods to compare isovolumic cardiac function in isolated hearts of varying sizes. American Journal of Physiology, 272: H501-H510.

13. Mirsky I (1979). Elastic properties of the myocardium: a quantitative approach with physiological and clinical applications. In: Handbook of Physiology. The Cardiovascular System. The Heart. Section 2. Vol. 1. Chapter 14. American Physiology Society, Bethesda, MD, USA, 497-531.

14. Suga $H$ (1971). Left ventricular time-varying pressure/volume ratio in systole as an index of myocardial inotropism. Japanese Heart Journal, 12: 153-160.

15. Monroe RG, La Farge CG, Gamble WJ, Hammond RP \& Gamboa R (1966). Left ventricular performance and blood catecholamine levels in the isolated heart. American Journal of Physiology, 211: 12481254.

16. Gamble WJ, Conn PA, Kumar E, Plenge R \& Monroe RG (1970). Myocardial oxygen consumption of blood-perfused, isolated, supported, rat heart. American Journal of Physiology, 219: 604-612.

17. Werner JC, Whitman V, Fripp RR, Schuler HG \& Morgan HE (1981). Carbohydrate matabolism in isolated, working newborn pig heart. American Journal of Physiology, 241: E364-E371.

18. Swindle MM \& Bobbie DI (1986). Anatomic and anesthetic considerations in experimental cardiopulmonary surgery in swine. Laboratory Animal Science, 36: 357-361.

19. Horneffer PJ, Gott VL \& Gardner TJ (1982). Swine as a cardiac surgical model. In: Behring E (Editor), Swine as Models in Biomedical Research. lowa State University Press, Ames, IA, USA, 321-325.

20. Li G, Sullivan JA, You JM \& Hall RI (1998). Effect of pressure on 
myocardial function after 6-hour preservation with blood cardioplegia. Annals of Thoracic Surgery, 65: 115-124.

21. Gregg D (1963). Effect of coronary perfusion pressure or coronary flow on oxygen usage of the myocardium. Circulation Research, 13: 497-500.

22. Buckley NM, Porter EP \& Jedeikin LA (1970). Effect of varying coronary perfusion on ventricular function in isolated dog hearts. American Journal of Physiology, 218: 1399-1405.

23. Ross Jr J, Kolcke F, Kaiser G \& Braunwald E (1963). Effect of alteration of coronary blood flow on the oxygen consumption of the working heart. Circulation Research, 13: 510-513.

24. Arnold G, Morgenstern C \& Lochner W (1970). The autoregulation of the heart work by the coronary perfusion pressure. Pflügers Archiv, 321: 34-55.

25. Lochner W, Arnold G, Kosche F, Miessner E \& Neitzer A (1968). The importance of the perfusion pressure in the coronary arteries for the contractility and the oxygen consumption of the heart. Pflügers Archiv, 299: 339-356.

26. Abel RM \& Reis RL (1970). Effects of coronary blood flow and perfusion pressure on left ventricular contractility in dogs. Circulation Research, 27: 961-971.

27. Knowlton FP \& Starling EH (1912). The influence of variations in temperature and blood pressure on the performance of the isolated mammalian heart. Journal of Physiology, 44: 206-219.

28. Anrep GV (1912). On the part played by the suprarenals in the normal vascular reactions of the body. Journal of Physiology, 45: 307-317.

29. Feigl E (1983). Coronary physiology. Physiological Reviews, 63: 1161.

30. Monroe RG, Lafarge CG, Gamble WJ, Rosenthal A \& Honda S (1968). Left ventricular pressure volume relations and performance as affected by sudden increases in developed pressure. Circulation Research, 22: 333-334.
31. Budrikis A, Bolys R, Liao Q, Ingemansson R, Sjoberg T \& Steen S (1998). Function of adult pig hearts after 2 and 12 hours of cold cardioplegic preservation. Annals of Thoracic Surgery, 66: 73-78.

32. Stahl LD, Weiss HR \& Becker LC (1988). Myocardial oxygen consumption, oxygen supply/demand heterogeneity and microvascular patency in regionally stunned myocardium. Circulation, 4: 865-872.

33. Eberli FR, Apstein CS, Ngoy S \& Lorell BH (1992). Exacerbation of left ventricular ischemic diastolic dysfunction by pressure-overload hypertrophy. Circulation Research, 70: 931-943.

34. Feldman AM, Weinberg EO, Ray PE \& Lorell BH (1993). Selective changes in cardiac gene expression during compensated hypertrophy and the transition to cardiac decompensation in rats with chronic aortic banding. Circulation Research, 73: 184-192.

35. Lorell BHL, Wexler S, Momomura S, Weinberg E \& Apstein CS (1986). The influence of pressure overload left ventricular hypertrophy on diastolic properties during hypoxia in isovolumically contracting rat hearts. Circulation Research, 58: 653-663.

36. Glass MG, Fuleihan F, Liao R et al. (1993). Differences in cardioprotective efficacy of adrenergic receptor antagonists and $\mathrm{Ca}^{2+}$ channel antagonists in an animal model of dilated cardiomyopathy. Effects on gross morphology, global cardiac function, and twitch force. Circulation Research, 73: 1077-1089.

37. Sagawa K, Suga H, Shoukas AA \& Bakalar K (1977). End systolic pressure volume ratio: a new index of contractility. American Journal of Cardiology, 40: 748-753.

38. Burkhoff D \& Sagawa K (1986). Ventricular efficiency predicted by an analytical model. American Journal of Physiology, 250: R1021R1027.

39. Ko W, Zelano JA, Lazzaro R, Lazenby WD, Hamilton T, Isom W \& Krieger KH (1992). Superiority of the University of Wisconsin solution over simple crystalloid for extended heart preservation. A study of left ventricular pressure-volume relationship. Journal of Thoracic and Cardiovascular Surgery, 103: 980-992. 